\title{
PESQUISADORAS NEGRAS NA DOCÊNCIA DO ENSINO SUPERIOR: UMA ANÁLISE A PARTIR DA PERSPECTIVA (AUTO)BIOGRÁFICA
}

\author{
BLACK RESEARCHERS IN HIGHER EDUCATION TEACHING: AN ANALYSIS FROM \\ THE (AUTO) BIOGRAPHICAL PERSPECTIVE
}

\author{
INVESTIGADORAS NEGRAS EN LA DOCENCIA DE LA ENSEÑANZA SUPERIOR: \\ UN ANÁLISIS A PARTIR DE LA PERSPECTIVA (AUTO) BIOGRÁFICA
}

\section{Claudia Miranda}

Universidade Federal do Estado do Rio de Janeiro - Brasil

\begin{abstract}
Resumo: As estratégias de sujeitas negras, que se profissionalizam, com vistas a alcançar deslocamento de seu status sócio educacional, são problematizadas a partir de uma análise (auto)biográfica. Como parte das alternativas de construção do conhecimento arrisco-me a sugerir, como uma contribuição transgressora, alguns atalhos experimentados no percurso de estudante universitária, pesquisadora e professora do ensino superior. Apresento interseções e contornos investigativos sobre a formação acadêmica tomando como objeto uma travessia insurgente em instituições públicas. O ponto de partida é uma análise onde a presença negra e feminina na docência do ensino superior ganha relevo.
\end{abstract}

Palavras chave: Pesquisadoras Negras; Docência no ensino superior; Perspectiva (auto)biográfica

\begin{abstract}
The strategies of black subjects, who become professional, with a view to achieving displacement of their socio-educational status, are problematized from a (self) biographical analysis. As part of the alternatives of knowledge construction I venture to suggest, as a transgressive contribution, some shortcuts experienced in the course of university student, researcher and teacher of higher education. I present intersections and investigative contours about the academic formation taking as object an insurgent crossing in public institutions. The starting point is an analysis where the black and female presence in teaching higher education is highlighted.
\end{abstract}

Keywords: Black Researchers; Teaching in higher education; (Self) biographical perspective

Resumen: Las estrategias de sujetas negras, que se profesionalizan, con miras a alcanzar desplazamiento de su estatus socioeducativo, son problematizadas a partir de un análisis (auto) biográfico. Como parte de las alternativas de construcción del conocimiento me arriesgo a sugerir, como una contribución transgresora, algunos atajos experimentados en el recorrido de estudiante 
universitario, investigadora y profesora de la enseñanza superior. Presento intersecciones y contornos investigativos sobre la formación académica tomando como objeto una travesía insurgente en instituciones públicas. El punto de partida es un análisis en donde la presencia negra y femenina en la enseñanza superior gana relieve.

Palabras clave: Investigadoras Negras; Docencia en cursos universitarios; Perspectiva (auto) biográfica

\section{Introdução}

Em "Metamemória-memórias: travessia de uma educadora" (SOARES, 2001), uma das provocações é que o passado não é o antecedente do presente. Na melhor hipótese é a sua fonte, sobretudo, quando se considera que é pelo presente que se explica o passado. Como Magda Soares, fiz uma opção pela vida universitária sem deixar de criticar as insuficiências e contradições da estrutura e organização de Instituições de Ensino Superior (IES). A formação de novas/os pesquisadoras/es na pós-graduação, esbarra cada vez mais em temáticas insurgentes e dissonantes na medida em que outras presenças se estabelecem sendo esse um dos resultados das políticas de democratização das universidades brasileiras.

Os conteúdos programáticos privilegiados na transposição didática realizada nas disciplinas "Metodologia da Pesquisa em Educação" e "Currículo" - ministradas por mim dependem de problematizações relacionadas aos conhecimentos silenciados na prescrição curricular. Essa seleção nos convoca a recuperar significações pouco criticadas no âmbito das referidas propostas. São dinâmicas que exigem conexões multifacetadas e movimentos mais complexos para assim, insurgirmos conjuntamente, com outras perguntas sobre o "corpus científico". Sob essa orientação, encontrei alguns achados nos estudos voltados para a História de Vida de Professoras/es, estudos sobre Auto(biografia) e estudos sobre Etnopesquisa. Em um esforço de mapear produções de referência e comprometidas com releituras metodológicas, ganharam importância estudos produzidos, no Brasil, sobre a valorização de travessias marginalizadas.

Em "Docência Memória e gênero: estudos alternativos sobre a formação de professores" (BUENO et al, 1993, p. 304), ganha ênfase a preocupação com as memórias colocadas em segundo plano. Para as autoras "é importante mostrar a existência e o porquê de determinadas memórias ficarem à margem". Analisam aspectos dessa exclusão e revelam um tipo de incômodo causado pelo fosso existente. Com isso, "torna-se importante mostrar que 
essas memórias nem sempre são anuladas, mas podem resistir numa existência subterrânea e irromper na memória pública quando brechas no sistema ideológico o permitem” (Ibidem).

Sob tal perspectiva, arrisco-me a sugerir, como uma contribuição transgressora, alguns (des)caminhos experimentados no percurso que fiz como professora e pesquisadora no ensino superior. Levo em conta as pistas de Magda Soares (2001) sobre o passado como fonte do presente e, ao acessar a produção mencionada, convenço-me a adotar reorientações em termos de perspectivas ainda não exploradas, estando no centro, abordagens (auto)biográficas. $\mathrm{O}$ intuito foi promover interseções multifacetadas para uma análise onde a presença negra e feminina na docência do ensino superior ganha relevo.

\section{Por que (auto)biografia?}

Abordagens (auto)biográficas admitem a auto representação como constructo, sugerem compêndios outros de significação da identidade docente e assumem contornos metodológicos que favorecem sobreposições de experiências adquiridas na trajetória profissional. Alinho-me às orientações presente nos estudos de Christine Delory-Momberger (2012) e Denice Bárbara Catani (2005) pelo interesse de alcançar aproximações significativas acerca da formação de pesquisadoras negras, docentes do ensino superior e de pós-graduação.

$\mathrm{Na}$ África e na sua diáspora, a realidade cotidiana apresenta condicionantes de distintos níveis, relacionados à vida material (níveis de pobreza e miserabilidade) e esses aniquilam segmentos de mulheres africanas e afrodescendentes submetidas aos efeitos do sistema colonial-patriarcal. Ao contrário da brancura, a "negrura", historicamente, não foi constituída como um capital, no sentido bourdieusiano ${ }^{1}$ e, para não perder de vista a tese de Sueli Carneiro (2003, p. 119), sobre mulheres em movimento, vale ressaltar essas representações. Mulheres negras estão representadas como "antimusas"2" e esse fenômeno demandou reações como "trazer à tona as implicações do racismo e do sexismo que condenaram as mulheres negras a uma situação perversa e cruel de exclusão e marginalização sociais" (CARNEIRO, 2003, p.129). Em seu quadro propositivo, localiza uma variável racial

\footnotetext{
${ }^{1}$ Sobre o conceito de capital, refiro-me ao trabalho desenvolvido por Pierre Bourdieu acerca dos tipos examinados para entender a estruturação social. Ao analisar o capital simbólico, por exemplo, considera que esse diz respeito ao prestígio que uma pessoa alcança, por onde transita. Considera diferentes formas de "riqueza" na estruturação de contextos sociais e entende que um indivíduo tem mais ou menos inserção conforme a posse desses capitais.

${ }^{2}$ A compreensão desse lugar de fixação das mulheres negras como "antimusas", é de Sueli Carneiro no seu trabalho "Enegrecer o Feminismo: a situação da mulher negra na América Latina a partir de uma perspectiva de gênero" (2001). A autora faz a análise com base nos modos de representação desumanizadoras em diferentes contextos.
} 
que exigiu algo definido como "gêneros subalternizados": refere-se tanto a "uma identidade feminina estigmatizada (das mulheres negras), como a masculinidades subalternizadas (dos homens negros) com prestígio inferior ao do gênero feminino do grupo racialmente dominante (das mulheres brancas)". Destaca a dupla subvalorização, um efeito do rebaixamento promovido pelo racismo e, para as mulheres negras, esse efeito - no status de gêneros -, garantiu degenerescências identitárias deixando-as, por exemplo, em desvantagem sócio educacional. Carneiro destaca a urgência de uma extraordinária mobilidade social para que atinjamos os mesmos níveis de desigualdades existentes entre homens e mulheres brancos. Ao rechaçar os efeitos dos estigmas e da degenerescência mencionados pela autora, agrego, como um recurso (auto)biográfico, a construção de um diário de bordo concebendo-o como um mosaico de sobreposições, como parte de um desenho analítico sobre as alternativas engendradas para mobilidade acadêmica.

Por outra parte, a problematização adotada inclui alguns marcadores discursivos bem como traços do percurso que fiz, com ênfases que revelam, também, um "complexo de relações entre o indivíduo e suas inscrições e entornos (históricos, sociais, culturais, linguísticos, econômicos, políticos); entre o indivíduo e as representações que ele faz de si próprio e das suas relações com os outros" (DELORY-MOMBERGER 2012, p.523). Minha jornada como formanda, formada, pesquisadora e profissional do ensino superior, se aproxima das categorizações adotadas por Delory-Momberger de "agir estratégico", "agir progressivo", e "agir na expectativa", que a autora interpreta como partes do "esquema de ação" (WALTER R. HEINZ Apud DELORY-MOMBERGER, 2012).

Em sentido mais amplo, o encaminhamento que adoto tem como eixo axial as travessias de um corpo feminino e negro que se movimenta nas instâncias do sistema educacional em diferentes períodos cumprindo etapas de formação e profissionalização. Entendo que:

[...] o deslocamento de intelectuais originárias de países periféricos, tais como o Brasil e a Índia, constitui-se em um modo de insurgência pela ausência da dimensão dialógica que agrega sua agência. Trata-se de um projeto que visa o compromisso com a emancipação do grupo de origem, mas, que oferece uma oportunidade de localização dos diferentes tipos de 'Outros' produzidos na violência colonial/patriarcal. Pode ser também, uma tática a ser adotada pelo segmento que desfruta, em certo sentido, de espaços onde suas narrativas têm penetrado ainda que por frestas transformadas $\mathrm{em}$ atalhos potenciais (MIRANDA,2014, p.2). 
A possibilidade de deslocar-me, rumo à universidade, esteve marcada pelo ethos comunitário familiar, mas, ao mesmo tempo, os vínculos com associações e coletivos do Movimento Negro, impactaram minhas escolhas como partícipe de processos antirracistas no campo da pesquisa acadêmica. De certo, a atuação de pesquisadoras negras como docentes do ensino superior se converte em um importante objeto de pesquisa para investigadoras/es de diferentes países, sobretudo, para entendermos os processos vivenciados e as alternativas adotadas frente aos obstáculos.

Nos achados que faço para localizar os ganhos da (auto)biografia, convenço-me da relevante contribuição advinda dos contornos metodológicos sugeridos pelas/os autoras/es que consolidam essa abordagem. Em "A leitura da própria vida e a escrita da experiência de formação" Denice Catani (2005, p. 31) trabalhou com "sentidos atribuídos pelo sujeito que experimenta a vida escolar e/ou reconstrói suas trajetórias de formação" e, suas preocupações epistêmicas giram em torno das possibilidades de aproveitar tais memórias para reformulações relevantes para a produção da história da Educação. Em seu argumento "questões teóricas como as das relações entre memória ou história ou entre escrita de si e reinterpretação de si ou entre motivações sociais e escrita autobiográfica merecem consideração ao se examinar [...] na perspectiva de integrá-las à produção da história da educação". Com essa inclinação, entendo que as estratégias de sujeitas negras, que se profissionalizam e que empurram obstáculos feito atletas, com vistas a alcançar o êxito no deslocamento de seu status e promover mobilidade, é um dado para a historiografia que se dedica a acompanhar mudanças profundas no século XXI.

A tese intitulada "Relações raciais, África e Afro-brasileiros no currículo: percursos formativos de formandos de História da UFRJ" (BARCELLOS, 2018, p.4) reforça o lugar de importância das análises (auto)biográficas e se destaca como uma "pesquisa-formação" implicando o autor que, por sua vez, assume as afetações pessoais ocorridas ao longo do processo de elaboração. Barcellos faz do trabalho, um espaço de reflexão (auto)biográfica propiciando, às/aos participantes, o status de coautoras/es. Apoiou-se em exercícios de rememoração dos modos como se relacionam e aprendem suas/seus interlocutoras/es. De certo, as narrativas que emergiram no ateliê biográfico, produzido coletivamente, revelaram suas estratégias e críticas acerca da formação acadêmica. Os resultados acenderam contornos significativos da (auto)biografia e de suas variações, podendo contribuir com as análises sobre a escrita de si e, portanto, abrir outras frestas para a ampliação da perspectiva de (auto)biografar-nos. 
Entendo que, nos caminhos investigativos tomados por nós, “certas informações observações aparentemente isoladas e discrepantes, podem vir a se constituir em importantes elementos na elucidação das questões de estudo" (LUDKE; ANDRÉ, 2012, p. 43). Ao mesmo tempo, faz sentido articular as travessias e as práticas vividas na docência e na pesquisa ressaltando como "a construção da narração inscreve-se na subjetividade e estrutura-se num tempo, que não é linear, mas num tempo da consciência de si, das representações que o sujeito constrói de si mesmo" (SOUZA, 2007, p. 68). Conforme o autor, as abordagens experenciais tomam a escrita de si como uma alternativa na construção do conhecimento apostando em contribuições, por exemplo, para o campo da história da educação e para a área da formação docente.

\section{Diário de bordo e ressignificação de uma travessia}

Antes de chegar ao curso superior, ainda vinculada ao ensino médio, fui selecionada para uma bolsa de incentivo à pesquisa no Projeto "Educação e saúde: uma proposta de trabalho comunitário", na Fundação Oswaldo Cruz (FIOCRUZ). Com esse ingresso, fiz contato com diferentes pesquisadoras/es, médicas/os sanitaristas e educadoras/es influenciadas/os, também, por outras/os estudiosas/os, estando nesse quadro Victor Vincent Vala $^{3}$ (1937-2009). Passei a conhecer estudos de autoras/es como Paulo Freire naquela instituição e, ao circular nas diferentes unidades, tive acesso às suas bibliotecas. Acompanhei reuniões de planejamento e de elaboração de ações de intervenção, ao mesmo tempo em que aprendia sobre seu perfil como instituição de pesquisa. Numa "ambiência internacional", convivia com grupos diferentes de jovens profissionais de Saúde Pública e da Educação e essa travessia, ainda no ensino médio, gerou em mim, um tipo de convicção acerca do papel social que tinha como oriunda da juventude católica na década de 1990, no Rio de Janeiro.

Já como estudante de graduação (1987-1992) de uma Universidade Federal de Ensino Superior (IES) de grande prestígio - mais precisamente da Faculdade de Letras da UFRJ -, ouvi de algumas professoras, em diferentes semestres, que o curso era para jovens que não precisavam trabalhar. Aprendi a lidar com essa reação dentro de instâncias públicas criadas sob a égide da democracia e da "educação para todos". Entendo que as práticas discursivas adotadas estavam marcadas, dentre outras coisas, pelo incômodo da chegada - mesmo que tímida -, de jovens das periferias do Estado do Rio de Janeiro e, portanto, faziam parte das

3 Uma de suas obras de referência é "Para compreender a pobreza" (2005). Suas pesquisas influenciaram a visão sócio educacional de gerações de estudiosos/as sanitaristas - entre outras carreiras - da área de Saúde Pública. 
estratégias acionadas no ethos universitário existente. Foi nessa mesma IES que aprendi sobre os modos de se viver o acontecimento universitário como "a outra" da situação e, portanto, de viver como alguém "fora do lugar" 4

Retornei para uma segunda graduação (1994), no Instituto de Filosofia e Ciências Sociais (IFCS) e, entre 1994 e 1997 cursei parte daquele currículo, passei a trabalhar nas suas bibliotecas e conheci profissionais que diziam: para fazer o mestrado tens que aproveitar esse contato com as estantes de livros e periódicos, tomar gosto ao ponto de querer viver por eles. Levava tudo ao pé da letra e ouvia, atenta, as palavras de incentivo da bibliotecária Eloisa Helena Pinto de Almeida, uma servidora negra, que ocupava o cargo de chefia em um setor a biblioteca - de grande influência para nós, as/os estudantes. Sua prática discursiva cotidiana, se constituía em uma espécie de "pedagogia do convencimento", a cada novo passo dado, com vistas a mudar meu status de universitária, sua opinião tinha peso para minhas futuras decisões. Em diferentes fases, voltei ao IFCS para contar-lhe sobre as etapas superadas: Passei para a rede pública de ensino; Vou para a Espanha estudar nas férias; Fui aprovada para o Mestrado em Educação”; Estou trabalhando na docência do ensino superior; Entrei para o doutorado.

A bibliotecária-chefe, uma servidora negra, como eu, foi espelho, foi uma das mais importantes referências que tive no âmbito da UFRJ. Considero importante rememorar tais episódios numa digressão pautada na valorização dos encontros, na valorização das influências de profissionais interlocutoras/es e que experimentei no percurso feito entre o Fundão (Faculdade de Letras), a Praia Vermelha (Faculdade de Educação) e o Centro da Cidade (IFCS).

O encontro com a pesquisadora Vanilda Paiva (1995) e a oportunidade de ser bolsista de Iniciação Científica (IC), do Instituto de Estudos da Cultura e Educação -(IEC/CEDES), na pesquisa "Qualificação, mudança de status e riscos pessoais nas formas alternativas de inserção no mundo do trabalho" (1995-1997), mudou as perspectivas de ingresso no mundo universitário. Com a especialista de projeção nacional, aprendíamos que o objetivo de tudo aquilo, vivenciado em grupo, era fazer pós-graduação, e que: a Iniciação Científica está organizada, na universidade, com o propósito de formar novas/os pesquisadoras/es. Esse foi o peso que carreguei ao apresentar um projeto, sob sua supervisão, para a seleção do

4 Adoto a explicação de Edward Said inserida em sua obra "Fora do Lugar: memórias' (2004), um livro onde o autor palestino e migrante assume as suas opções pelo lugar fronteiriço e vivendo no chamado "primeiro mundo" como intelectual da periferia. Também, como o autor, entendo essas recomposições de nós mesmos/as, sujeitas/os da diáspora africana e deslocadas/os, representadas/os socialmente como "fora do lugar", uma visão concebida pelos processos colonizadores. 
Mestrado, no Programa de Pós-graduação em Educação da UFRJ. Na entrevista, fui arguida por Alda Judith Alves Mazzotti, com quem trabalhei, a posteriori, investigando trabalho infanto-juvenil e fracasso escolar. Essa entrada, segundo Mazzotti, se justificava pela minha atuação como docente do ensino fundamental (SMERJ) e médio (Secretaria Estadual de Educação).

O foco no cotidiano das instituições escolares ratificou alguns aspectos apreendidos, anteriormente, quando partícipe do projeto (FIOCRUZ) que privilegiava a educação popular e seus desafios frente às condições de trabalho precário e a situações de alta complexidade.

Fiz parte de um pequeno coletivo que se constituiu por afinidade, por reconhecimento de múltiplas insuficiências que nos afetavam naquele período em que ingressávamos como universitárias/os na Faculdade de Letras (UFRJ). Refiro-me a uma rede de solidariedade visando, à época, garantir aprendizagens dissidentes e complementárias, algo avaliado muito depois de formadas/os e que não tínhamos dimensão. Ao mencioná-lo aqui, rememoro as travessias considerando-o reflexo do apoio mútuo, do impulso gerador de recomposição de significação. Juntávamos com alguns outras/os jovens oriundas/os de distintas regiões - bem como a migrantes de zonas mais distantes -, e discutíamos sobre aquela cultura organizacional. Juntávamos como estratégia de permanência em uma esfera considerada inóspita. Essa foi mais uma possibilidade de composição identitária e que gerou a motivação para outros investimentos fundamentais na vida de qualquer jovem universitária/o.

O campus do Fundão contava com o projeto cultural "Quintas Musicais" que recebia artistas como Simone, João Bosco, Djavan, Gonzaguinha, Belchior, entre outros/as. Nesses espaços constituídos a partir de uma espécie de "hibridismo performático", conhecíamos as pautas dos segmentos atuantes na cidade universitária e, aos poucos, traduzíamos outros modos de ser estudantes deslocados/as e por vezes, invisíveis. Era, também, uma experiência de confronto com diferentes realidades pela distinção de classe ali existente. Ao mesmo tempo, no ir e vir no campus, pode-se considerar que fizemos parte de uma espécie de cultura de internacionalização institucional já que a "Universidade do Brasil" (UFRJ) se constituía como uma das principais IES, com acordos de cooperação incluindo diferentes países africanos estando entre esses, Angola, Moçambique, Gana, Guiné Bissau e Cabo Verde.

A aproximação com grupos de outras culturas favorecia estranhamentos importantes e criativos afetando a relação com os espaços de convívio sendo frutífera pelas aprendizagens multidimensionais obtidas. Aprende-se como a vida universitária pode ser uma promessa de formulação de outras visões de mundo e de amadurecimento intelectual. As greves 
deflagradas em pleno período acadêmico e as assembleias com o grito de luta por uma "universidade gratuita", de "qualidade" e "para todos", se convertiam em rituais de passagem. Nessa pulsação, havia uma forte presença de servidoras/es, estudantes que se misturavam na defesa da IES e experimentávamos a ocupação política e cultural.

$\mathrm{Na}$ Faculdade de Letras, desfrutávamos de propostas mobilizadoras e sobre tal aspecto lembro-me do impacto causado pela "Semana Machado de Assis", por se tratar de um evento internacional, com a circulação de pesquisadoras/es estrangeiros/as advindos de países distintos. Por via dos projetos de extensão, tivemos o pesquisador e escritor Joel Rufino dos Santos (1941-2015) como professor e com ele discutíamos sobre o exílio, racismo e a politização dos estudantes. Incluo, nesse ir e vir, os bate-papos informais nos corredores e no gabinete do referido professor. Por tudo isso, considero essas oportunidades de encontros, parte de um ritual de superação que faz a diferença se consideramos as inúmeras reações a uma "presença outra" e "fora do lugar". Essa distinção era também por conta de uma performance negra que se iniciava mesmo que timidamente. Joel Rufino dos Santos retornava do exílio e era, também, um "outro", um proponente de leituras enviesadas e, assim, favoreceu outros achados epistemológicos para jovens estudantes. Em sua prática discursiva, incluía a experiência como ativista político e sua passagem por diferentes lugares do mundo chamando nossa atenção para a sua experiência no continente africano. Para ele a literatura que produzimos não dava conta das Áfricas que herdamos como país afrodescendente.

Aprendemos, ainda, sobre a distinção que um diploma promove, sobre o valor da pesquisa acadêmica e sobre porque deveríamos aproveitar, ao máximo, os espaços disponibilizados naquela faculdade. Pouco a pouco, tomávamos contato com um currículo oculto, algo além das disciplinas do curso e, nesses interstícios (Projetos e Cursos de Extensão, Festivais, Ciclos de oficinas), fazíamos atravessamentos que promoveram um percurso inesperado, forjado com iguais, com uma pequena "comunidade inventada" que se reconhecia pela condição de insurgência. As propostas de extensão, de ensino e de pesquisa potencializaram nossa aprendizagem e permitiram que, Joel Rufino dos Santos estivesse ali, naqueles anos de 1990, como docente, como partícipe de um curso de extensão podendo influenciar nossas "releituras" acerca daquele universo.

A UFRJ ocupou (e ocupa), no imaginário social, um lugar de destaque em termos do seu papel como instituição inauguradora. Hoje, com reservas de vagas ${ }^{5}$, a luta pela

\footnotetext{
${ }^{5}$ Sobre isso, recomendo consulta aos dados sobre o processo de adesão da UFRJ ao Enem/SiSU e ainda a implantação da Lei n ${ }^{\circ} 12.711 / 12$. A referida lei institui a reserva de um mínimo de $50 \%$ de vagas para estudantes
} 
democratização, por dentro, já apresenta conformações dissonantes sendo esse um resultado positivo apesar do longo período de recusa de tal abertura. A complexidade que marca as IES, vistas por dentro, se aproxima da análise de Jessé de Souza (2009, 108-109) em "Ralé brasileira: quem é e como vive":

[...] toda a nossa socialização e aprendizado é, em grande medida, um aprendizado das necessidades dessas instituições e de como podemos nos moldar a essas necessidades. Desse modo, o que é preciso perceber é que tais instituições, longe de serem "neutras", possuem toda uma "hierarquia valorativa", que estipula e estimula certas "virtudes" e condena e estigmatiza outras. Dito de outro modo e indo direto ao ponto, mercado e Estado "criam", no sentido forte desse termo, um certo tipo de indivíduo e de comportamento individual e condenam todas as outras formas possíveis ao esquecimento e ao estigma social da pré-modernidade, do delinquente e do marginalizado.

Se assim for possível considerar, passa a ser imprescindível ocuparmos as IES com fóruns permanentes que possam indagá-las sobre a sua importante tarefa frente aos dilemas pelos quais o Brasil tem enfrentado. A hierarquia valorativa das IES se sustenta, na maioria das situações, a partir de estratégias de estigmatização, de um tipo de seleção interna afetando, sobremaneira, grupos racializados. Ainda sobre essa vinculação, na década de 1990, na UFRJ, cabe reconhecer que, outros subgrupos se forjaram em diferentes unidades. Naquele mesmo período, outras jovens negras passaram por essas esferas e, de certo, uma pesquisa sobre egressas/os da UFRJ encontrará pequenos coletivos que assim se forjaram e que fizeram parte de sua história institucional. Mesmo que invisibilizados, estão em seus registros e podem revelar, de certo, histórias comuns sobre como se movimentaram pequenos coletivos considerados fora do lugar. Para famílias negras, esses resultados representam êxito e promovem clãs inteiros, em alguns casos além de servir como estratégia para impulsionar projetos de inserção na formação superior. Caberia sugerir análises focadas nas histórias de famílias lideradas por mulheres pobres e negras, como é o caso aqui tratado.

Mesmo com a presença de pai e irmão (filho mais velho), a liderança de uma migrante mineira, casada e com quatro filhos (três meninas), definiu estratégias de mobilidade educacional. Sua organização afetou os resultados de inserção das filhas e esse protagonismo, refletia as utopias com a vida futura além de potencializar nossas inclinações. Formamo-nos em instituições públicas federais (UFF, UNIRIO e UFRJ), conforme o planejamento de uma mãe que tinha como profissão ser "do lar" dedicando-se a educar seu filho e suas três filhas. 
Como resultado dessa conformação familiar, passo a valorizar o conhecimento legitimado socialmente e, ao longo do percurso como estudante, como partícipe da juventude católica, como ativista do Movimento Social Negro, tenho trabalhado com o ideário da cooperação mútua e com a possibilidade de coautoria. Participar de processos de luta por justiça implica assumir outras agendas sendo uma delas a inclusão de segmentos historicamente deixados à margem.

\section{Educação básica e pós-graduação: deslocamentos e mudança de status}

Meu vínculo com o sistema educacional foi como professora de Espanhol, em meados da década de 1990 atuando em cursos de idiomas, no Ensino Médio (Estado) e no Ensino Fundamental (Município). Ingressei na pós-graduação em 1998 e ao longo dos três anos como mestranda (Faculdade de Educação da UFRJ) cursei disciplinas diversas com destaque para uma específica, privilegiada pela importância do tema - Sociologia da Educação. Com o pesquisador responsável ampliei os conhecimentos sobre a área bem como sobre as contribuições de Pierre Bourdieu (1930-2002) para o campo da pesquisa sobre sistemas de ensino. As análises e pressupostos centrais, desenvolvidos pelo autor, ganharam importância nas atividades que se seguiam no período de formulação da dissertação.

Um episódio ocorrido nesse processo, ganhou importância pelas consequências que causou na percepção sobre a qualificação no nível da pós-graduação e na atividade avaliativa de culminância, obtive um resultado surpreendente, conforme a declaração feita em sala, no ato de entrega da prova escrita. Seja pela forma como a notícia foi emitida, seja pelo fato de ter sido a última estudante a receber de volta, sua avaliação e tomar conhecimento da famigerada nota "oito", estava explícito que para o docente responsável, tratava-se de "uma jovem fora dos padrões acadêmicos", "fora do lugar", uma mestranda com uma nota surpreendente quando comparada à média obtida pelo grupo inserido na disciplina. Ao declarar: você me fez uma grata surpresa soube que se tratava de uma saga cruzar as fronteiras existentes nesse contexto de formação. Não reagi, não elaborei resposta e creio que essa "não reação", pode ser lida como uma espécie de anestesia, algo que Frantz Omar Fanon (1925-1961) descreveu em "Peles Negras Máscaras Brancas" (2008) e que, a meu ver, é um dos pontos de partida para nossas agendas e começar a enfrentar epistemologicamente, o ranço colonial nesses contextos. 
As representações construídas sobre sujeitas/os racializadas/os fazem parte da problemática privilegiada no campo da pesquisa sobre desigualdades raciais e, a inserção na área, garantiu maior domínio desse tipo de fenômeno envolvendo "outsiders" e "estabelecidos", se considerarmos o quadro teórico de Norbert Elias (2000). No mesmo período e, após a conclusão das disciplinas curriculares, fui aceita como orientanda de Alice Ribeiro Casimiro Lopes e, produzi a dissertação "Conhecimento escolar em língua portuguesa: um estudo da transposição e/ou mediação didática em livros escolares de nível fundamental" (2001). Esse vínculo com a pesquisadora, marcou as escolhas futuras para minha performance intelectual além de indicar possibilidades de realizar cruzamentos significativos como discutir políticas curriculares versus movimentos sociais em perspectiva comparada, na América Latina. As discussões que Lopes assumiu, incluindo "transposição" e "mediação" didáticas, se desdobraram e influenciam, até hoje, minhas opções de estudo. Com seu incentivo direto, ingressei na docência do ensino superior (2001) e fiz parte do corpo docente de uma IES privada por oito anos formando um número expressivo de trabalhadoras/es de creches da Prefeitura do Rio de Janeiro, entre outros grupos. Esses encontros favoreceram a composição de outras estratégias de formação, mas dessa vez, com profissionais que atuam, também, nas IES públicas. Com essas/es foi possível, de alguma forma, entender a situação de estudantes das classes empobrecidas nos cursos de Pedagogia, além de acompanhar histórias de vida de profissionais que atuavam com dificuldade pela ausência de uma formação sólida. Éramos doutoras/es e doutorandas/os e dependíamos de inserção profissional prévia visando participar, a posteriori, de seleções para IES pública.

Já no período seguinte, entre 2002 e 2006 o doutorado (UERJ) foi sob a orientação do pesquisador Pablo Gentili e, nessa universidade alguns desdobramentos merecem destaque. Fui assistente de coordenação do "Programa Políticas da Cor no Brasil" (Laboratório de Políticas Públicas da UERJ) bem como organizadora da coleção de livros "Políticas da Cor" do mesmo programa. Tratava-se de um período de efervescência político-ideológica por conta das disputas retóricas envolvendo a implementação de medidas de cotas ${ }^{6}$. Além disso, a participação no "Projeto Espaços Afirmados" que se anunciava como uma proposta de Núcleo de Estudos Afro-brasileiros (NEAB), favoreceu aproximações com associações e coletivos diversos do Movimento Social Negro. Essas tarefas exigiram presença efetiva no campus universitário e exigiu o apoio para a organização de fóruns permanentes objetivando a

\footnotetext{
${ }^{6}$ Recomendo a tese de Elielma Ayres Machado (2004) "Desigualdades raciais e ensino superior: um estudo sobre a introdução das leis de reservas de vagas para egressos de escolas públicas e cotas para negros, pardos e carentes da UERJ (2000-2004)".
} 
promoção de espaços de diálogo na comunidade presente incluindo estudantes e intelectuais negras/os de todo o país, com vistas a garantir novas percepções sobre o tempo presente e a luta antirracista. Influenciou, inclusive, minhas opções de análise para a pesquisa intitulada "Narrativas subalternas e políticas de branquidade: o deslocamento de afrodescendente como processo subversivo e as estratégias de negociação na academia" (2002-2006).

Uma performance intelectual-acadêmica outra ganhava robustez já que essa presença no campus da UERJ-Maracanã adensava minhas análises sobre a relevância da presença de segmentos comprometidos com a garantia de maior mobilidade para as populações negras e a efetiva disputa pela ampliação de vagas nas IES. Nesse processo, reconheço o valor da promoção de fóruns no âmbito do Laboratório de Políticas Públicas (LPP) e dos confrontos retóricos - desdobramentos das reações advindas do corpo discente. Realizávamos críticas efetivas sobre o formato da política de inclusão na UERJ.

As diferentes passagens que recupero podem ser analisadas como ancoragens, como parte de uma via crucis implicando processos emancipatórios e contra hegemônicos em um período relevante, para a História da Educação Universitária. De certo, minhas opções pela docência (desde 1990) refletem parte das influências obtidas na vida escolar e ainda a admiração que sentia por profissionais engajados/as na defesa da educação pública de qualidade. Minha fixação como docente (desde 2002) de cursos de formação de professoras/es, tem demandado novas problematizações filosóficas e pedagógicas. Todas essas preocupações facilitam a apreensão do que proponho aqui, como abordagem.

Em outros termos, defendo como imprescindível olharmos para as pesquisas em curso, sobre (auto)biografia, para promovermos o invisível e realocarmos saberes da trajetória de pesquisadoras negras. Reconheço, no percurso, uma espécie de migração, um tipo de atravessamento ignorado mas que tem a ensinar sobre o que é a promoção de deslocamentos de estratos deixados à margem no interior das universidades de prestígio. Uma pergunta significativa seria: quais aprendizagens os percursos realizados favorecem? Sônia Kramer (1999, p.130) compreendeu a "ação pedagógica como prática social e cultural procurando entender o presente com o olhar iluminado pelo passado - ou por experiências passadas [...]". Do mesmo modo, ganha relevo a pesquisa de Denice Bárbara Catani (2005, p.32) sobre leitura da própria vida e a escrita de experiência de formação:

Questões teóricas, como as das relações entre memória ou história ou, entre escrita de si e reinterpretação de si ou entre motivações sociais e escrita autobiográfica, merecem consideração ao se examinar tais obras, na perspectiva de integrá-las à própria produção da história da educação. 
A meu ver, as autoras confirmam as urgências mencionadas anteriormente, sobre a acomodação de fontes não consideradas, fontes que se alinham às propostas de memória de trajetórias de pesquisadoras da educação superior, por ser esse um mosaico complexo e potente de vivências clandestinizadas ${ }^{7}$. Vinculações com os movimentos sociais, influências de pensadoras da diáspora e da África, bem como a escolha de objetos de pesquisa com foco nas desigualdades raciais, podem ser interpretados como parte da centralidade dada às experiências obtidas nos percursos feitos às margens do sistema educacional. Ao mesmo tempo, reconheço as disputas epistemológicas em curso tendo como âncora, compêndios de grande capilaridade que absorvem as teses de pensadoras como Bell Hooks, Lélia Gonzalez, Angela Davis, Neusa Santos Souza, Sueli Carneiro, Audre Lorde, Chimamanda Adichie, Virgínia Leone Bicudo, entre outras. São influências efetivas e em larga escala que se apresentam como base para a preparação de uma comunidade feminina e negra que reivindica lugares sociopolíticos, sendo, um desses, o ingresso e permanência no mundo da pesquisa acadêmica disputando sentidos de produção de conhecimento.

Um dos argumentos que defendo, exige que se observe o modus operandi afrofeminino de reivindicação, um dispositivo ofuscado, na maioria das vezes, onde não se considera essa dimensão.

\section{Proposições insurgentes}

Adotar a linguagem exigida para a performance investigativa, implica cooperação mútua e outros agenciamentos. Com o intuito de corresponder ao que se espera das/os pesquisadoras/es ingressantes, tenho instituído parcerias interinstitucionais para apresentar propostas tais como um observatório das formas de deslocamento feminino e negro considerando a importância desse recurso. O foco é o campo da História da Educação Universitária, concebendo o desafio de acompanhar as idiossincrasias que marcam o início de uma era, deixando, no centro dessas formulações, o avanço de um tipo de agência que ganha volume. Ao considerar as percepções de Catani, "pode-se facilmente observar a presença forte do recurso a fontes memorialísticas, literárias ou autobiográficas como elementos

\footnotetext{
7“"Clandestinização" é um conceito desenvolvido por Santiago Arboleda Quiñonez em seu livro "Le han florecido nuevas estrellas al Cielo: suficiencias íntimas y clandestinización del pensamiento afro colombiano (2016). Refere-se a negação da produção cultural e intelectual proveniente das matrizes africanas existentes na América Latina.
} 
significativos para o conhecimento da educação em períodos diversos" (CATANI, 2005, p.32).

Os anos de inserção na pesquisa e na docência ganham novo status frente ao que analisa Catani sobre as fontes memorialísticas. Ao explicar essa vertente - ao meu ver, oxigenante e de valorização do percurso dos profissionais, que, antes, foram iniciados por outras tantas -, o mote seria entender os lugares possíveis de penetração de segmentos femininos fixados como periféricos nas arenas onde o trabalho intelectual é a centralidade. Esses resultados indicam aspectos significativos a serem incorporados nas pesquisas sobre história das instituições universitárias. Nas IES, os reflexos desses efeitos nos convocam a rever itinerários no sentido de recompor sua missão pública. Ser pesquisadora e docente demanda comprometimento com a reinvenção e garantia de legitimidade de uma esfera imprescindível para elaborarmos um projeto de país atento ao dilema do racismo à brasileira. O racismo institucional é um dos problemas fundamentais nessa problematização.

Nos exemplos que busco para o trabalho colaborativo na pesquisa, encontro ressonância na história de luta de outras sujeitas assumindo o que pontua Jessé de Souza ao desvelar os sustentáculos das esferas que negam os grupos racializados e, historicamente, colocados à margem das esferas do Estado. Alinhada a essa análise, importa observar como intelectuais negras disseminaram tecnologias de sobrevivência e sobre isso ressalto o argumento de Sônia Beatriz dos Santos (2009, p.280) sobre o lugar das mulheres negras na história contemporânea:

As organizações não governamentais de mulheres negras no Brasil têm representado importantes espaços políticos e de resistência contemporâneos na luta contra formas de opressão na sociedade, tais como racismo, sexismo, heterossexismo, lesbofobia, homofobia, discriminação de classe, intolerância religiosa e cultural, dentre outras. Essas organizações estão inseridas no contexto mais amplo do movimento social de ONGs no Brasil e na região latino-americana.

Os aspectos ressaltados dão base para a proposta de retomada de leituras sobre essa trajetória onde a cartografia dessas ancoragens, com a agenda antirracista, passa a ser uma exigência. Ao considerar ações envolvendo profissionais negras dos sistemas de ensino (educação básica e superior) bem como suas diferentes vinculações nas instâncias da sociedade mais ampla, me vejo como parte desse movimento e os percursos institucionais realizados na UNIRIO, ganham maior destaque. Os silêncios mencionados bem como as metodologias de clandestinização de subjetividades transformadas em espaços vazios, nos processos coloniais e patriarcais, são pontos centrais e engrossam as denúncias que a pesquisa 
acadêmica, em sentido mais amplo, pode realizar. Com esse escopo busca-se entender as formas possíveis de intervir.

A Escola de Educação da Universidade Federal do Estado do Rio de Janeiro - UNIRIO - tem sido um espaço de confluências que definem, enviezadamente, o acontecimento universitário. Novas exigências se impõem para um projeto institucional ampliado de formação contínua. Se assim admitirmos, essas agendas insurgentes forçam outros modos de concepção das demandas sociais e revelam oportunidades antes desprezadas. O ponto a ser valorizado é o diálogo com a educação básica e com seus/suas praticantes. Refiro-me àquelas pessoas que se desdobram como docentes e a mais expressiva das inspirações que localizo tem a ver com ambiências multiculturais, concebidas para ampliar o diálogo universidadeescola. Do mesmo modo, os fóruns como o Encontro Nacional de Prática de Ensino (ENDIPE), que se preocupa com a formação continua e outras práticas. Uma de suas idealizadoras, a pesquisadora Vera Candau (1997, p.78), afirma que os estudos sobre cotidiano escolar se desenvolvem no Brasil, particularmente, a partir da década de 1980 e a preocupação com essa problemática vincula-se ao movimento de uma revisão crítica que provoca uma forte renovação do ensino e da pesquisa, no período citado. Em outro lugar, Candau e Sacavino (2010, p.14) realizaram um estudo sobre a produção dos Grupos de Trabalho das Reuniões Anuais da Associação Nacional de Pós-Graduação e Pesquisa em Educação (ANPEd), no período de 2003-2008 e o objetivo foi mapear as preocupações existentes sobre abordagens interculturais. Encontraram no "GT de Educação Popular", os resultados mais expressivos. Não obstante e, alinhada ao que sustentam as autoras, defendo como singular, a proposição de novos estudos sobre a densidade teórico-filosófica presente no conjunto de trabalhos apresentado pelo GT 21 (Relações Étnico raciais e Educação). A ideia é que tenhamos em conta achados sobre justiça curricular e epistêmica nas interseções com os espaços propostos, pelo Movimento Negro e suas (e seus) dinamizadoras/es. O "GT 21" da Anped, pode ser definido como uma comunidade de pesquisadoras/es insurgentes, que nasce do exercício retórico de proponentes como Iolanda de Oliveira e Petronilha Beatriz da Silva entre outras/os -, envolvidas na sua criação. Alinhada a essas trajetórias de investigação, reconheço suas pegadas como parte de um processo emancipatório e libertador. É resultado de aprendizagens contra hegemônicas alcançadas a contrapelo e que merecem maior visibilidade nos estudos sobre pesquisadoras/es negras/os no ensino superior.

Desde a ANPEd e observando as chamadas do ENDIPE, considero oportuno que assumamos, como indispensável, a trajetória da luta antirracista no campo educacional e no 
Rio de Janeiro, não se pode entender a condição pluricultural e as perspectivas interculturais sem o legado, por exemplo, do "Projeto Zumbi dos Palmares" dinamizado por educadoras e ativistas como Vanda Ferreira e Adélia Azevedo. No âmbito da Secretaria de Educação do Estado do Rio de Janeiro, visava garantir a preservação da memória afrodescendente. Na contracorrente, inauguram um modus operandi pautado na criatividade e resistência política com o objetivo de "deflagrar um processo de reconhecimento da cultura afro-brasileira como parte integrante da política cultural da Secretaria Municipal de modo a promover a promoção do saber imanado desta cultura no currículo escolar" (FERREIRA, 1987, p. 72). Ao produzir dados sobre o percurso da "luta educacional antirracista" (grifos meus) levada a cabo, conforme os exemplos trazidos aqui, indica-se outras possibilidades de concepção desses processos e das ambiências de aprendizagens decoloniais ${ }^{8}$. Ao considerar esses fios, recomponho minha identidade docente, e assumo o lugar de importância da luta que vi de perto como ativista e como membro do GT 21 desde a sua criação.

No exame das formas possíveis de intervir, como pesquisadora negra, alternativas viáveis exigem o trabalho em rede e nessa empreitada, alguns princípios ajudam na concepção de propostas. Sigo alinhada ao ideário que sustenta o "GT 21" da ANPEd, procurando formular outros percursos investigativos e interferir no campo da pesquisa da área. Faz mais sentido perguntar sobre como o compromisso teórico-epistêmico demanda insurgência e garantia de vozes clandestinizadas, conforme indicam os estudos de Santiago Arboleda Quiñonez (2016). De certo e caminhando, também, no contra fluxo, encontro brechas para problematizar a desvalorização das experiências profissionais convertidas em episódios corriqueiros no cotidiano..

\section{Formação em rede e pesquisa (auto)biográfica}

Em diálogo com outras profissionais comprometidas com a escola pública, a ideia de instituir um trabalho colaborativo e de pesquisa acadêmica, de pesquisa sobre outras metodologias, nasce e se consolida na Rede Carioca de Etnoeducadoras Negras criada em 2015. O coletivo docente é fruto também dessas inspirações mútuas envolvendo a universidade.Com essa conformação busquei apoio entendendo a importância desse acúmulo e o projeto tem potencializado um ir e vir em rede.

\footnotetext{
${ }^{8}$ Sobre essa temática, consultar o artigo "Pedagogias decoloniais e interculturalidade: desafios para uma agenda educacional antirracista”, publicado na Revista Educação em Foco ( 2016).
} 
Além de valorizar processos de cooperação envolvendo escolas e universidades, fez sentido observar as reações ao vínculo com redes de outro país da região da América Latina para entender idiossincrasias e especificidades dessas experiências. O ethos educacional problematizado exige outras definições para Educação, exige um movimento pedagógico mais plural e menos unívoco. Uma agenda que subsidie uma Educação para as relações étnicoraciais, ou, como querem os afros colombianos para a Etnoeducação que garanta a chamada "educação própria”. Nesse processo, o projeto é parte de um constructo onde os anos de atuação docente fundamentam as percepções da formação de professoras/es.

Nesses interstícios, a vinculação com as profissionais que dinamizam a Educação para relações étnico raciais é o grande salto de qualidade. As imagens abaixo fazem parte das memórias das três edições já realizadas:

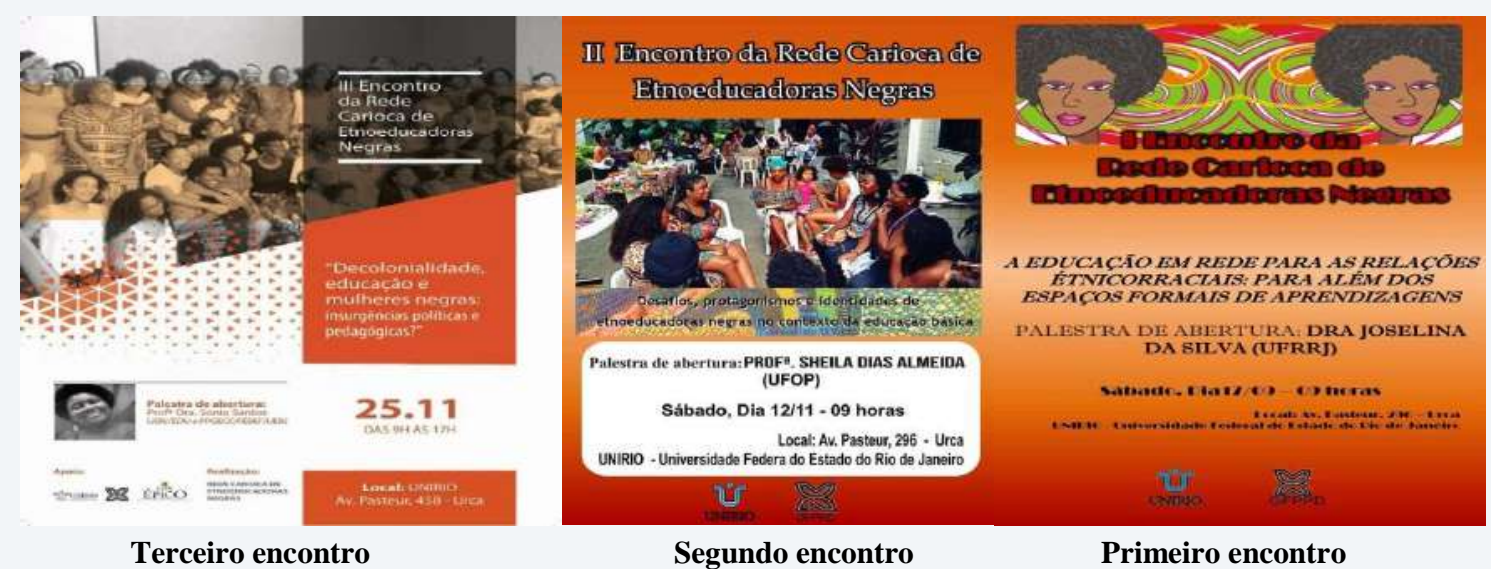

Após três encontros anuais (2015, 2016 e 2017), a Rede Carioca de Etnoeducadoras Negras revela uma vocação para internacionalização9 e para atuar como proponente em diferentes fóruns da área da Educação. Além desse traço, contamos com a adesão de importantes pesquisadoras negras com vínculos na docência do ensino superior e com elas, sustenta-se a proposta pela exemplaridade de suas trajetórias consolidadas no campo da pesquisa. Notadamente, as histórias de inserção e luta profissional refletem as opções políticopedagógicas e realocam a auto representação construída, a meu ver. Em rede, aprendo que o trabalho em coautoria, se converte em uma estratégia de conexão com as esferas envolvidas (escolas e universidades) e, das conversas com os/as interlocutores/as que temos em diferentes países, tem sido possível valorizar as iniciativas já existentes, fora do Brasil. No diálogo consolidado, expando as concepções epistêmica e filosófica sobre os sentidos que esses

${ }^{9}$ Em 2017 participamos (nove componentes da Rede Carioca de Pesquisadoras Negras) da XIII Jornadas Nacionales de Historia de las Mujeres /VIII Congreso Iberoamericano de Estudios de Género como proponentes da mesa 63 intulada "Historia de las mujeres negras en América Latina". 
espaços ganham na luta antirracista e na promoção de novas entradas que possam apoiar a formação de jovens estudantes negras, futuras pesquisadoras e docentes.

Minhas apostas relacionam-se com as convicções adquiridas nesse percurso experimentado na contramão, nos interstícios e à contrapelo. Tal como o argumento de Denice Bárbara Catani (2005, p.37) sobre a escrita de si e a memória da História da Educação, assumo como indispensável essa visão e localizo a capilaridade das abordagens (auto)biográficas. Um achado que se revela no percurso se relaciona com o seguinte argumento:

Não só estão em cena, nessas produções, os sentidos atribuídos às experiências de aprendizado, formação e escolarização, mas também aquelas relacionadas à escolha e experiências do exercício de uma profissão. Desentranha-se da escrita dessas obras modos de seleção com o trabalho, representações, valores e decisões que impregnam a orientação da vida [...], além de elementos úteis para que se compreenda a história da profissão dos professores.

Considero que os estudos (auto)biográficos acrescentam dimensões epistêmicas e filosóficas e, quando o foco está nas trajetórias docentes, nos movimentos sociais, nas perspectivas descolonizadoras para a educação superior, localizo a proposição de fundo, de cartografar o fluxo de jovens oriundas/os de trajetórias semelhantes e insisto com a reinscrição temática na História da Educação Superior no século XXI dando ênfase aos desdobramentos da agenda de reivindicação por mudanças curriculares. Entender essa caminhada implica o reconhecimento do papel das profissionais que disputam outras epistemologias.

\section{Algumas conclusões}

Ao considerar parte de uma trajetória insurgente e de formação profissional, devo assumir a importância dos diálogos alcançados com interlocutoras/es encontrados em espaços de formação como, por exemplo, o Bloco Afro Agbara Dudu e o Instituto de Pesquisa das Culturas Negras (IPCN). Foram essas as primeiras instituições no Rio de Janeiro com as quais mantive contato efetivo, no final dos anos de 1990. O quarto dos fundos - às vezes cubículos cheios de entulho -, a cozinha e as áreas de serviço das casas e mansões das classes médias brasileiras, são, por exemplo, ambientes por onde a maioria dos nossos corpos circulou. São eventos traumáticos no cotidiano experimentado nesses formatos de inserção das mulheres negras no mundo do subemprego. Não estamos em grande número em nenhum outro espaço 
da sociedade e, nos espaços da universidade pública, somos vistas como uma "novidade intragrupo", sujeitas fora do lugar. Em outros estudos, tenho insistido com o tema da educação e da interculturalidade e a tese (2002-2006) realizada sobre o que é a cultura universitária do início do século XXI - e seus desafios frente a insurgência de um "movimento negro em ascensão" - indica parte desse exercício teórico.

A atuação das pesquisadoras negras inclui as lutas sociais e de certo, a opção pela docência no ensino superior, implica a teorização sobre as multidimensões assumidas politicamente. Em outros termos, é importante que se investigue sobre as bases de apoio para essa performance. Sugiro, como uma questão para novas pesquisas (considerando as facetas da ascensão das pesquisadoras ativistas do Movimento Negro), análises sobre a relação que estabelecem com o tempo da produção. Para alcançar outras estratégias e outras tecnologias de deslocamento político e insurgência epistêmica, importa que valorizemos esses (des)caminhos. Sugiro que tenhamos, como prioridade, conformações mais em rede visando a promoção de experiências interculturais entre pesquisadoras situadas na universidade e na escola. Que tenhamos propostas concebidas dialogicamente e em colaboração, frente aos desafios intragrupos que nos são apresentados.

Essas percepções refletem as aprendizagens obtidas a partir do contato com os projetos apresentados com destaque. O tempo da pesquisa, para mulheres negras, deve ganhar centralidade e atravessar nossas análises em teses sobre as formas de insurgência adotadas. De certo, existe um caminho já trilhado em diferentes lugares do mundo e mesmo que localizadas em diferentes contextos, suponho que nossas conexões são imprescindíveis e ocorrem não apenas fisicamente. Existem identificações simbólicas, obtidas por agendas afirmativas elaboradas e executadas nos diversos contextos e que recebem adesão intergeracional. Como tarefa, seria importante incluirmos mosaicos conceituais como aqueles já publicizados por sujeitas tais como as professoras Patricia Hill Collins, Angela Davis e Bell Hooks. Refiro-me as suas experiências docentes e de enfrentamento nesse espaço de politização das respectivas travessias como ativistas do antirracismo e como pensadoras negras que atuaram/atuam no ensino superior.

\section{REFERÊNCIAS}

BARCELLOS, Vitor Andrade. Relações raciais, África e Afro-brasileiros no currículo: percursos formativos de formandos de História da UFRJ. (tese). Rio de Janeiro, UFRJ, 2018. 
BUENO, Belmira Oliveira; SOUSA, Cynthia Pereira de; CATANI, Denice Bárbara; SOUZA, Maria Cecília C. C. de. Docência, memória e gênero: estudos alternativos sobre a formação de professores. Psicologia USP, SP, 4 (1/2), p .299-318, 1993.

CANDAU, Vera; SACAVINO, Susana Beatriz. Contribuições do GT de Educação Popular da ANPEd para a educação intercultural http://33reuniao.anped.org.br/33encontro/app/webroot/files/file/Trabalhos\%20em\%20PDF/G T06-6318--Int.pdf.

CARNEIRO, Sueli. Mulheres em movimento. Estudos Avançados 17 (49), 2003.

CARNEIRO, Sueli. Enegrecer o feminismo: a situação da mulher negra na América Latina. Revista LOLA Press, n. 16, novembro de 2001.

CATANI, Denice Barbara. As leituras da própria vida e a escrita de experiências de formação. Educação e Contemporaneidade, Salvador, v. 14, n. 24, p. 31-40, jul./dez., 2005

DELORY-MOMBERGER, Christine Abordagens metodológicas na pesquisa biográfica. Revista Brasileira de Educação, v. 17 n. 51 set.-dez. 2012.

ELIAS, Norbert; SCOTSON, John L. Os estabelecidos e os outsiders: sociologia das relações de poder a partir de uma pequena comunidade. Tradução de Vera Ribeiro. Rio de Janeiro: Jorge Zahar, 2000.

FERREIRA, Vanda Maria de Souza. Projeto Zumbi dos Palmares. Cadernos de Pesquisa, n. 63 nov. 1987.

HYPOLITO, Álvaro L. Moreira. Trabalho docente, classe social e relações de gênero. Campinas, SP: Papirus, 1997.

LUDKE, Menga; ANDRÉ, Marli E. D. A. Pesquisa em educação: abordagens qualitativas. São Paulo, E.P.U, 2012.

KRAMER, Sônia. Leitura e escrita de professores em suas histórias de vida e formação. Cadernos de Pesquisa, n. 106, março de 1999.

MIRANDA, Claudia. Intelectuais afro-brasileiras e suas contribuições para uma crítica póscolonial feminista. In: II Congreso de Estudios Poscoloniales y II Jornada de Feminismo Poscolonial, 2014, Buenos Aires. II Congreso de Estudios Poscoloniales y II Jornada de Feminismo Poscolonial. Buenos Aires: Instituto de Altos Estudios Sociales, 2014. v. 1. p. 120.

QUIÑONEZ, Santiago Arboleda. Le han florescido nuevas estrellas al cielo: suficiencias íntimas y clandestinización del pensamiento afrocolombiano. Santiago de Cali: Poema su casa editorial, 2016.

SAID, Edward. Fora do lugar: memórias. São Paulo: Companhia das Letras. 2004.

SOARES, Magda. Metamemória-memórias: travessia de uma educadora. Petrópolis RJ: Ed.Vozes, 2001. 
SOUZA, Elizeu Clementino de. (Auto)biografia, histórias de vida e práticas de formação. Salvador: EDUFBA, 2007.

SOUZA, Neusa Santos. Tornar-se negro ou as vicissitudes da identidade do negro brasileiro em ascensão social. Rio de Janeiro: Edições Graal, 1983.

SOUZA, Jessé de. Ralé brasileira: quem é e como vive. Belo Horizonte: Editora da UFMG, 2009.

STEPHAN, Beatriz González. Modernización y disciplinamiento. La formación del ciudadano: del espacio público y privado. In: STEPHAN, Beatriz González; LASARTE, J.; MONTALDO G.; DAROQUI, M. J. (orgs). Esplendores y miserias del siglo XIX: cultura y sociedad en América Latina. Caracas: Monte Ávila Editores, 1995.

VAZ, Daniele de Deus França Gomes Galvão. Redes de etnoeducadores/as no trânsito Brasil - Colômbia: um estudo a partir das pedagogias decoloniais e da interculturalidade crítica. Rio de Janeiro: Universidade Federal do Estado do Rio de Janeiro (Dissertação de Mestrado), 2017.

\section{SOBRE A AUTORA:}

\section{Claudia Miranda}

Doutora em Educação pela Universidade do Estado do Rio de Janeiro (UERJ). Professora da Universidade Federal do Estado do Rio de Janeiro (UNIRIO). Docente do Programa de PósGraduação em Educação da UNIRIO. Líder do grupo de pesquisa Formação de professores, Pedagogias Decoloniais, currículo e interculturalidade: agendas emergentes na escola e na universidade. E-mail: mirandaunirio@gmail.com 